\title{
Ensino Remoto e Anos Iniciais do Ensino Fundamental: reflexões em torno da docência e de algumas escolhas didático-pedagógicas para o ensino da leitura e da escrita
}

Remote education and Elementary School: reflections around teaching and some educational pedagogical choices for teaching reading and writing

\section{Marília Forgearini Nunes}

Universidade Federal do Rio Grande do Sul - UFRGS - Rio Grande do Sul - Brasil

\section{Renata Sperrhake}

Universidade Federal do Rio Grande do Sul - UFRGS - Rio Grande do Sul - Brasil

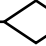

Resumo: Este texto apresenta uma reflexão em torno da prática pedagógica voltada aos Anos Iniciais do Ensino Fundamental com crianças, especialmente com foco na Leitura e na Escrita, no contexto do Ensino Remoto. Recuperamos princípios docentes que reforçam o papel da professora como profissional da educação, embasando-nos em autores como Narodowski (2020), Perrenoud (2001) e Larrosa (2018). Assim, elencamos algumas propostas pedagógicas que têm como motivação experiências do cotidiano familiar e doméstico envolvendo diferentes gêneros textuais, discutindo sua potencialidade e sua possibilidade no ensino remoto. Ao final, tecemos considerações sobre as dificuldades do ensino remoto com os sujeitos dos Anos Iniciais do Ensino Fundamental e sobre o currículo desta etapa.
\end{abstract}

Palavras-chave: Anos Iniciais do Ensino Fundamental. Ensino remoto. Docência. Leitura. Escrita.

\begin{abstract}
This text presents a reflection on the pedagogical practice at Elementary School with a focus on Reading and Writing, in the context of Remote Education. We recovered teaching principles that reinforce the teacher's role as a professional who deals with education, based on authors such as Narodowski (2020), Perrenoud (2001) and Larrosa (2018). Thus, we list some pedagogical proposals that are motivated by everyday family and domestic experiences involving different textual genres, discussing their potential and their possibility in remote education. At the end, we make considerations about the difficulties of remote education considering the students at Elementary School and the curriculum of this level.
\end{abstract}

Keywords: Elementary School. Remote teaching. Teaching. Reading. Writing. 


\section{Introdução}

Motivadas por uma conversa transmitida ao vivo ${ }^{1}$ que realizamos ainda no início da pandemia², iniciamos as reflexões que apresentamos neste texto. O ensino remoto surpreendeu em um início de ano letivo. O afastamento repentino do ambiente escolar, da sala de aula e do contato presencial com os alunos subverteu boa parte do que sabíamos sobre a organização da prática pedagógica em todos os níveis de educação.

Nesse texto, nossos apontamentos estarão em torno da prática pedagógica voltada aos Anos Iniciais do Ensino Fundamental (1ำ ao $5^{\circ}$ ano) com crianças a partir dos seis anos, especialmente com foco na Leitura e na Escrita. Especificamos os sujeitos dessa prática pedagógica, mas não ignoramos que o fazer pedagógico, do modo como conhecemos e abordamos no processo e contexto de formação docente, é interativo-presencial em boa parte das práticas, independente do público e da sua faixa etária. Mesmo na contemporaneidade, quando a presença da tecnologia é massiva, o ensino e a aprendizagem acontecem por meio de ações presenciais, olho no olho, primordialmente no ambiente da escola e da sala de aula. Esse entendimento que nos coloca em xeque no momento em que a escola e a sala de aula tornamse lugares inacessíveis e pouco seguros à saúde de todos. O ensino híbrido já possui discussões teóricas e experiências práticas, mas entendemos que ainda não chegaram à sala de aula da Educação Básica, principalmente em se tratando de escola pública.

Confusas, em meio a essas mudanças, o caminho que assumimos aqui neste texto, foi recuperar princípios docentes que reforçam o nosso papel como profissionais da educação. Depois disso, assentadas nesses princípios encaramos uma nova realidade em que ensino e aprendizagem precisam acontecer, e a prática pedagógica precisa ser (re)organizada e, assim, elencamos algumas propostas pedagógicas que têm como motivação experiências do cotidiano familiar e doméstico envolvendo diferentes gêneros textuais. Assim, o que pretendemos nesse texto é elaborar uma possível resposta à seguinte questão: como pensar a docência e organizar algumas práticas pedagógicas para os Anos Iniciais do Ensino Fundamental no contexto do ensino-aprendizagem em tempos de Ensino Remoto?

A elaboração dessa resposta nos leva a encarar o ensino e aprendizagem de maneira nova, sem dúvida, mas sem nos perdermos do papel docente como responsável pelo fazer pedagógico, com um saber profissional e singular próprio. Muda-se o contexto, mas não os personagens que permanecem atuantes, professora ${ }^{3}$ e estudantes seguem como atores principais desse novo roteiro da educação em tempos de pandemia de COVID-19.

\section{Docência e ensino remoto: um re-agir}

Nossa argumentação está baseada na crença de quem somos e no que fazemos, no compromisso assumido com a docência, com os alunos que recebemos em nossas aulas a cada ano ou semestre letivo. Essa crença provoca-nos a pensar como agir, a buscar soluções, a reinventarmo-nos como docentes. Essa reinvenção está assentada na ausência de espaços e objetos significativos da docência: a escola (como prédio físico), a sala de aula (com sua composição de quadro, cadeiras e classes), a ocupação do espaço da sala de aula (pelos corpos e pelas interações). Tudo isso não encontra apoio no cotidiano atual da docência e, por isso, desequilibra, provoca a prefixação das ações que acontecem a partir desses objetos e nos espaços de significação que citamos. É preciso se reinventar, recriar práticas e recursos, renovar métodos e técnicas, rever crenças, repensar a docência. É momento de (re)agir e reescrever princípios.

Toda essa revisão do ser e fazer na educação é também um desafio que pode ser paradoxal. Se antes vivíamos reiteradamente dizendo da necessidade de mudar a escola e tentando modificá-la, repetindo argumentos sobre a importância da tecnologia e ao mesmo tempo deixando-a de lado porque não sabíamos (e ainda não sabemos) muito bem como lidar com ela, agora fomos atropelados pela necessidade de tê-la, com todos os seus recursos e 
possibilidades de comunicação digital, para que a docência exista e possa acontecer. Desejávamos a mudança, a novidade e, de repente, ela tornou-se elemento central para o que é o ser e o fazer na profissão docente.

Apesar do fato de que a mudança e a inovação da educação de modo geral e, especificamente, do ensino sempre foram desejadas, a situação é paradoxal porque não foi o desejo o que motivou 0 novo modo de fazer a educação e ser docente. Todos os envolvidos nesse processo foram levados a mudar diante da pandemia de covid-19. Como nos disse Mariano Narodowski em suas "Onze teses urgentes para uma pedagogia do contra-isolamento":

Ninguém estava preparado para uma mudança tão abrupta, não apenas pela falta de capacidade tecnológica na maioria das escolas e lares, mas também porque quase todos os pais não escolheram voluntariamente se preparar para ensinar seus filhos. E, além disso, porque a imagem de uma "casa" na qual existem recursos materiais e culturais para educar as crianças como se fosse uma escola, corresponde apenas a uma parcela mínima da população mundial (NARODOWSKI, 2020, s.p.).

Tal constatação de Narodowski nos leva a pensar sobre a distinção entre espaços e relações associadas a cada um deles. A experiência escolar é, ou deveria ser, o encontro entre alunos, professores e conhecimento. Essa experiência tem um espaço que é comum, que se dá em torno de conhecimentos que são públicos, que são disponibilizados para uso livre (MASSCHELEIN; SIMONS, 2017). Além disso, essa experiência escolar se dá coletivamente, ela é compartilhada por uma turma inteira, e mediada por uma professora. Esses elementos que caracterizam a experiência escolar foram colocados em estado de suspensão.

Passamos a ter um novo cenário como espaço de realização do educar. A casa é um ambiente do âmbito do privado, do pessoal, do particular. Em geral, o Estado não interfere nas questões domésticas e familiares; ao passo que a escola é do âmbito do comum, do público, do compartilhado. As práticas que acontecem nesse espaço têm forte interferência do estado, elas são reguladas, avaliadas, geridas por ele.
Esse aspecto já nos aponta para a impossibilidade de replicar uma experiência escolar dentro das casas, nesse momento, pois "Aprender em casa não é um espelho do aprendizado na sala de aula. Nem mesmo um espelho quebrado. É outra experiência radicalmente diferente." (NARODOWSKI, 2020). E, talvez seja, justamente, nesse pensar uma "experiência radicalmente diferente" que estejam a potência e as possibilidades para criarmos nesse momento.

E que experiência de aprendizagem é essa, então, que pode ser assumida como caminho para o reagir da docência? Parece-nos que estamos tratando de uma aprendizagem em um sentido muito amplo, e bem menos estruturada que a aprendizagem escolar. Realmente, não se trata de reinventar práticas escolares. O que buscamos como argumento para essa reação que discutimos neste trabalho, é o aproveitar as situações da vida no espaço doméstico para aprender sobre diferentes práticas sociais e culturais, ressignificando a casa também como ambiente de aprendizagem com suas características e possibilidades. Concordamos com Narodowski quando ele diz que o "[...] pior desse presente é simular a escolaridade aonde não há" (NARODOWSKI, 2020, s.p.), onde ela não está.

O primeiro passo, portanto, seria justamente adaptar nossas expectativas, permitimo-nos uma maior flexibilidade, e seguindo o que o autor aponta, selecionar "[...] inteligentemente conteúdo, atividades, cuidados, quantidades e qualidades" (NARODOWSKI, 2020). Desse modo, essa seleção feita pelas escolas precisa ser sensível, considerando as possibilidades materiais e emocionais das famílias das crianças e também das professoras. Outro aspecto a ser considerado nessa seleção é o perigo da "novidade": não é apenas em razão de uma proposta ser realizada contando com recursos tecnológicos que ela se torna "boa", "interessante", "produtiva". O uso das ferramentas de comunicação digital e outras tecnologias que se fazem presentes nesse momento, e que para a maioria dos professores se constituem como uma novidade, não necessariamente trazem consigo, de forma inerente, um potencial para a 
aprendizagem. Devemos lembrar que qualquer recurso didático-pedagógico prescinde de mediação qualificada pelo docente, que responda a três questionamentos: 1) qual conhecimento ou habilidade está em jogo naquele recurso? 2) quem são as crianças que estão aprendendo com aquele recurso, o que elas já sabem e o que elas podem aprender? e 3) quais intervenções podem ser feitas, considerando a criança e o recurso, de modo a potencializar a aprendizagem? Assim, se recursos didáticos recorrentemente presentes nas salas de aula, como o livro didático por exemplo, podem ser muito bem explorados e podem gerar aprendizagens significativas, por outro lado, também podem ser alvo de práticas pouco produtivas, este mesmo raciocínio vale para o uso de recursos tecnológicos e digitais. Desse modo, seja nas práticas educativas que acontecem nas salas de aula, seja na reinvenção dessas práticas para o contexto do ensino remoto, a seleção, organização e mediação qualificadas de recursos pedagógicos é parte do trabalho do professor e compõe aquilo que é o seu saber profissional, independente do espaço onde a o processo educativo aconteça.

Philipe Perrenoud traz no título de um de seus livros algo que diz muito sobre o que é ser professora: "Ensinar: agir na urgência, decidir na incerteza" (2001). Se este enunciado já era adequado às condições usuais das salas de aula, ele se mostra mais adequado ainda neste momento em que a própria sala de aula encontra-se em suspensão. Consideramos que as palavras urgência e incerteza representam o movimento próprio do fazer docente e das práticas escolares, a possibilidade de vida que a docência carrega de modo inerente e atemporal. Ser professor, portanto, é ser agente de uma organização, ou seja, fazer parte de um conjunto, de um coletivo mais amplo; e também é ser artesão do seu fazer, escolhendo de modo solidário. A conjugação dessa coletividade e dessa artesania ${ }^{4}$ individual compõe a docência, que é carregada de responsabilidades assumidas por aqueles que a escolhem como profissão.

Diante, então, da necessidade de "agir na urgência e decidir na incerteza", o que os professores podem priorizar no momento de reinventar suas práticas para o ensino remoto? Consideramos que devem ser construídos princípios com intencionalidade e sensibilidade, pensando no vínculo com os alunos, no contexto de vida da criança, nos tempos e espaços disponíveis para o estudo nessa família, e nos conhecimentos que serão alvo das propostas. Salientamos que a construção desses critérios é feita com base em conhecimento profissional, que é próprio do professor como um profissional do ensino, tendo, portanto, o saber necessário para fazer tais escolhas, em articulação com os saberes que estão sendo construídos enquanto criamos e vivemos este momento.

3 Professora: agente da reação, da reorganização no contexto do ensino remoto

Antes de passarmos a algumas possibilidades para tentar responder à pergunta que motiva a escrita deste texto, queremos enfatizar um ponto: acreditamos que é a professora quem irá organizar a prática pedagógica no ensino remoto contando, o quanto for possível, com o apoio das famílias. Este é, sem dúvida, um desafio que se apresenta, visto que as professoras precisam descobrir como organizar o ensino para a aprendizagem aconteça sem a presença física de seus alunos diariamente.

A nossa crença é de que a relação entre professora e alunos individualmente, professora e turma, professora e professoras é o que poderá trazer/reforçar a unidade, ou seja, reforçar as diferentes interações inerentes à escola. Como estabelecer vínculo à distância? De modo remoto? Em busca de um caminho para construir uma resposta (porque resposta pronta ou única não há), encontramos a palavra interesse. No livro, $P$ de PROFESSOR (2018, p.237), Jorge Larrosa afirma: "[...] a palavra interesse tem esse "entre", o que tem interesse é o que é ou está entre, no meio, o que já é de todos em geral e, portanto, de ninguém em particular". Tal afirmação desafia a pensar sobre um modo de iniciar esse vínculo: como provocar o interesse tanto pelo aprendizado escolar quanto pelo 
que está em casa, no cotidiano familiar do estudante? A provocação que motivamos está assentada em encontrar um interesse que seja de todos, pertinente ao momento vivido, ao assunto, ao modo de olhar o mundo, ao modo de estarmos (con)vivendo. O cotidiano visto de modo sensível, pensamos que pode ser um caminho, um recurso didático acessível e atrativo se mediado com sensibilidade.

Dessa maneira, assumimos que a rotina e o cotidiano são palavras-chave para que o vínculo possa ser estabelecido, reorganizando o currículo e suas potencialidades. Cada professora, cada turma, cada grupo de alunos encontrará o que será foco de sua atenção naquele comum do dia-a-dia que precisa ser olhado de outra forma, subvertido, visto com surpresa, curiosidade. Entra em ação a sensibilidade para viver esse cotidiano com estesia, e não anestesiados, sentir o cotidiano, deter-se nos detalhes, apreciar, deixar o corpo sentir e fazer parte disso:

O enigma consiste em meu corpo ser ao mesmo tempo vidente e visível. Ele, que olha todas as coisas, pode também se olhar, e reconhecer no que vê então o "outro lado" de seu poder vidente. Ele se vê vidente, ele se toca tocante, é visível e sensível para si mesmo[...] Visível e móvel, meu corpo conta-se entre as coisas, é uma dela, está preso no tecido do mundo, e sua coesão é a de uma coisa (MERLEAU-PONTY, 2004, p.17)

As propostas que elencaremos a seguir têm como motivação algumas experiências do cotidiano familiar e doméstico. O trabalho da professora seria, além de angariar essas experiências com a sua turma de alunos, pensar formas de guiar a observação dessas situações e formas de registrá-las. Além disso, também se faz necessário discutir e analisar esses registros, seja na própria família, seja com os colegas da turma.

Pensamos em algumas práticas de leitura e de escrita que podem fazer parte da vida cotidiana da maioria das famílias ${ }^{5}$. Citamos uma que provavelmente esteja bem presente: as listas. Sérgio Costa, em seu "Dicionário de gêneros textuais" (COSTA, 2014, p.161), define a lista como "texto em que se relacionam pessoas ou coisas, obedecendose a uma ordem alfabética, numérica, temporal cronológica, etc.”. Podemos sugerir que a criança participe da escrita de listas no cotidiano familiar; que "colecione" as listas de supermercado ou de tarefas que circulam em casa. A partir delas é possível criar "listas fabulosas", como no livro Listas fabulosas da Eva Furnari (FURNARI, 2013). Um exemplo bem sugestivo para o momento, trazido pela autora, é a "lista de pequenas mudanças que dão grandes problemas". Outro livro que trata desse gênero é o Listografia (NOLA, 2014), em que temos listas de "desenhos animados favoritos", "lista de coisas que irritam você", e etc. Essas ideias podem ser produtivas para incentivar as crianças na atividade da escrita na escrita e também para ajudar a professora a conhecer essa criança, através de uma prática de escrita que se torna significativa na medida em que ressignifica uma prática vivenciada ou observada em casa.

Outro gênero que poderia ser explorado nesse contexto de ensino remoto é o diário. Uma das características desse gênero textual é se ater ao momento presente, registrando fatos do cotidiano, eventos do dia a dia (COSTA, 2012). Escrever um diário da quarentena possibilita a exploração de variadas formas de registro: imagens, fotos, recortes e colagens, escrita, gravações, etc. E ainda, na linha do que já referenciamos antes, possibilita observar o cotidiano e pensar sobre ele: observar o céu durante o dia e a noite; observar a rua em que mora (de dentro do pátio ou pela janela, é claro) - ver como está o movimento de pessoas, de automóveis, etc.; observar os insetos no pátio de casa (se há pátio), observar os animais de estimação e registrar comportamentos, etc. A professora poderia solicitar de seus alunos que fizessem registros desse tipo, variando em complexidade e em quantidade de informações de acordo com o ano escolar e com as habilidades de escrita já consolidadas de seus alunos. Ela também poderia indicar a leitura de diários ou de trechos de diários, como o Diário de Anne Frank (FRANK, 2000), por exemplo. O registro poderia ser feito por meio de escritas a mão ou digitalmente. Novamente, esses textos escritos, além de resgatar um gênero textual já pouco presente nas práticas de escrita atuais (ao menos com as características mais tradicionais desse gênero), seriam uma fonte de informações para a professora sobre o cotidiano dessas crianças, possibilitando estreitar o vínculo com elas.

Outra possibilidade seria as crianças gravarem pequenos áudios com cantigas de roda, canções rimadas, trava-línguas - tanto textos que sejam 
conhecidos pelas famílias, quando propostos como desafios pela professora - e após a gravação, compartilhar com a turma. Os textos da tradição oral estão presentes em várias práticas familiares, como as canções de ninar, as cantigas que acompanham brincadeiras, as cantigas de roda. Esses textos apresentam uma natureza poética e lúdica, sendo muitas vezes divertidos. Segundo Araújo (2011, p.27).

"[...] o vigor, a potência e a riqueza de trabalhar com esses textos com as crianças, especialmente as menores, está em explorar o seu caráter oral, sua dimensão lúdica, sua forma original, com seus objetivos primeiros, que é brincar, contar, cantar, desafiar, rir, interagir. Ato de linguagem em ação, jogo de linguagem e interação, herança cultural oral, memória, voz, brincadeira: esses aspectos não podem ser esquecidos, na abordagem desses textos, especialmente na Educação Infantil"

Morais (2019) aponta que esses textos são de fácil memorização, possuem vocabulário simples, contém muitas rimas, aliterações e repetições de palavras, o que confere a eles a sensação de se estar jogando ou brincando com as palavras. Assim, o enfoque do trabalho com esses textos poderia ter em primeiro plano a dimensão da Cultura Oral envolvida neles: cantar, brincar, ouvir, memorizar, conhecer esses textos. (ARAÚJO, 2011). Em segundo plano, devido às condições do ensino remoto, ficariam os aspectos relacionados à consciência fonológica e à alfabetização, mas que, ainda assim, poderiam ser explorados dependendo das condições desse ensino e das famílias envolvidas.

Um gênero textual que pode ser igualmente explorado é a receita culinária. Este gênero está vinculado a uma prática usual no ambiente familiar e pode ser aproveitada especialmente para leitura. Esse gênero se caracteriza pela predominância "[...] de uma linguagem instrucional com uso de formas verbais (imperativo, infinitivo) de valor imperativo ou impessoal" (COSTA, 2014, p.200). Além disso, a prática culinária, envolvendo o texto da receita, geralmente alterna os momentos de leitura com os momentos de preparação do prato/iguaria em questão, - que pode ser explorado pela professora especialmente com alunos mais velhos, uma vez que a fluência da leitura pode ser importante nessa situação. Para além da leitura, essa prática cotidiana também permite uma exploração sobre as quantidades, a transformação dos materiais - dos ingredientes - em relação à textura, cor, cheiro, sabor, etc.

Ainda em relação à leitura, estimular a leitura de obras literárias é algo extremamente necessário e rico para a experiência com linguagem de uma criança, mas sabemos que nem sempre estão presentes nas casas das famílias. Porém quando estiverem, essa leitura pode ser potencializada pela professora ao fornecer às famílias alguns encaminhamentos para essa prática, tais como conversar com a crianças sobre o que ela espera da história a partir do título ou da capa, fazer perguntas ao longo da leitura ou da contação da história, de modo que a criança possa prever ou inferir desfechos e acontecimentos, retomar elementos da história lida ou ouvida ao final da leitura ou contação. Convém destacar que há também os livros em formato e-book que podem ser acessados por dispositivos móveis6, e que a professora pode compartilhar com as crianças e suas famílias. Também a leitura de outros materiais que estejam disponíveis em casa, tais como embalagens, panfletos, etc., pode ser estimulada em pequenos desafios propostos pela professora.

A característica comum dos gêneros textuais mencionados acima é que eles estão presentes em práticas cotidianas ou familiares em que as habilidades de ler, escrever ou falar estão implicadas. Nesse sentido, salientamos o destaque feito pela Base Nacional Comum Curricular (BNCC) à organização das práticas de linguagem em campos de atuação, apontando "[...] para a importância da contextualização do conhecimento escolar, para a ideia de que essas práticas derivam de situações da vida social e, ao mesmo tempo, precisam ser situadas em contextos significativos para os estudantes" (BNCC, 2017, p. 84). Dentro os cinco campos de atuação citados na BNCC, o "Campo da vida cotidiana" está presente apenas nos Anos Iniciais do Ensino Fundamental e compreende "[...] práticas mais cotidianas em que a circulação de 
gêneros orais e menos institucionalizados é maior" (BNCC, 2017. p. 84).

Ao citar a BNCC e os campos de atuação em que ela organiza as práticas de linguagem não estamos dizendo que contemplar habilidades e conhecimentos listados na BNCC deva ser a principal preocupação no momento do ensino remoto. O que pretendemos é mostrar que os gêneros textuais vinculados às práticas do campo da vida cotidiana podem encontrar visibilidade no momento em que a professora vá selecionar e escolher os focos de seu planejamento para o ensino remoto.

\section{Considerações para finalizar o texto, mas não a discussão}

“Não há receitas para o novo. Não há poções mágicas. No contra-isolamento, há tudo o que pensar e o que fazer. Educação é a possibilidade do pensamento. $O$ pensamento é o vírus que devemos pegar" (NARODOWSKI, 2020).

O afastamento social imposto pela pandemia nos empurrou para fora da nossa zona de conforto de um modo sem precedentes em muitas situações e experiências do cotidiano. A experiência escolar e todas as ações nela implicadas foram centrais na nossa discussão aqui neste texto, e, tal como na afirmação de Narodowski na epígrafe acima, não há receitas prontas para o momento. Nossa intenção foi justamente exercitar o pensamento de modo a buscar estratégias viáveis para o ensino remoto.

Para finalizar, apresentamos duas reflexões. A primeira delas diz respeito aos sujeitos das turmas de Anos Iniciais do Ensino Fundamental e, especialmente, às crianças na etapa da alfabetização. Talvez sejam elas, no contexto da Educação Básica, após a Educação Infantil, as que demandem mais atenção de professores e da família nesse momento, pois essas crianças ainda não têm a autonomia que as crianças um pouco maiores têm para compreender as tarefas, fazer pesquisas, estudar por conta própria: "À medida que a idade dos alunos diminui, os alunos precisam cada vez mais do apoio de um adulto" (NARODOWSKI, 2020). Elas precisam de um mediador muito presente nos momentos em que a aprendizagem é um objetivo, e esse papel que é da professora no contexto da sala de aula presencial, está sendo feito de forma remota, por um lado, com o apoio de alguém da família, por outro com apoio nos recursos didáticos criados pela professora. Consideramos que essa característica do ensino remoto se constitui como um grande desafio tanto para professoras quanto para os responsáveis pelas crianças. Porém, do ponto de vista didáticopedagógico, fica a cargo das professoras a busca por alternativas para lidar com esse desafio, reinventando e recriando experiências de aprendizagem, com características talvez muito distantes daquelas que são vivenciadas presencialmente, porém sempre propostas com intencionalidade.

A segunda reflexão se assenta na consideração de que "O currículo da maior parte das instituições educacionais não foi criado para ser aplicado remotamente" (BEHAR, 2020, s.p). Desse modo, precisamos compreender que o ensino remoto, diferente da Educação a Distância, é uma solução emergencial para o momento e que, provavelmente, no retorno às atividades presenciais, as escolas e as redes de ensino precisarão revisitar e reorganizar seus currículos e fazer adequações de modo que as perdas em função das restrições impostas por essa forma emergencial de ensino sejam minimizadas ao máximo.

Diante desse contexto emergente que nos desacomoda há que se buscar alguma certeza. Encontramos base para buscarmos sustento na incerteza, e foi em torno dela que boa parte da nossa argumentação se construiu, na figura da professora. É da professora a voz e o fazer que podem auxiliar a superar as dificuldades, pelo conhecimento que tem do seu papel e das ações nele implicadas.

1 As transmissões ao vivo ou lives se disseminaram a partir do momento em que o afastamento social foi inevitável devido à pandemia de COVID-1. Mencionamos aqui a conversa "A criatividade e a experiência no cotidiano - ANOS INICIAIS EF" Disponível em:

https://www.youtube.com/watch?v=5YImE4xhDkM\&t=94 s. Acesso em: 20 nov. 2020.

2 Durante o ano de 2020, o mundo foi acometido por uma pandemia do novo Coronavírus, causador da COVID-19, doença que atinge principalmente as vias respiratórias. $O$ afastamento social foi recomendado 
como um dos principais meios de inibir a transmissão do vírus, o que motivou o fechamento de instituições de ensino e a implantação do ensino remoto para que o ano letivo tivesse continuidade.

3 Utiliza-se o termo "professoras" ao longo do artigo, pois a grande maioria das pessoas que trabalham em turmas de Anos Iniciais do Ensino Fundamental são do gênero feminino.

${ }^{4}$ Inspiramo-nos em Fabris (2015) e Larrosa (2018), que por sua vez se inspiram em Richard Sennett, ao usar o termo "artesania" para nos referirmos ao trabalho da professora pois "[...] remete à maestria, ao ser professor, às maneiras de fazer encarnadas no conhecimento sensível dos materiais, no uso conveniente dos artefatos, na precisão dos gestos, na adequação do vocabulário que nomeia tudo isso. A obra do artesão, seu ofício, mostra sua maestria, ou seja, ao saber incorporado, encarnado em seu mesmo corpo" (RECHIA; LARROSA, 2019, p.40).

5 Não temos a pretensão de dizer que são de todas as famílias - e aqui cabe uma investigação da professora a respeito disso.

6 Hoje temos disponíveis gratuitamente vários ebooks em diferentes sites e plataformas.

\section{REFERÊNCIAS}

ARAÚJO, Liane Castro de. ... Quem os desmafagafizar bom desmafagafizador será : textos da tradição oral na alfabetização. Salvador: EDUFBA, 2011, 64 p.

BEHAR, Patrícia Alejandra. O Ensino Remoto Emergencial e a Educação a Distância. In: Jornal da Universidade - UFRGS. Porto Alegre, 2020. Disponível em: $\quad<$ https://www.ufrgs.br/jornal/o-ensino-remotoemergencial-e-a-educacao-a-distancia/> Acesso em: 30 Ago. 2020.

BRASIL. Base Nacional Comum CurricularBNCC. Brasília: MEC, 2017. Disponível

http://basenacionalcomum.mec.gov.br/a-base Acesso: 18/06/2018.

COSTA, Sérgio Roberto. Dicionário de gêneros textuais. 3.ed. Belo Horizonte: Autêntica Editora, 2012.

FABRIS, Eli Terezinha Henn. A realidade do aluno no currículo escolar: a problematização de um imperativo pedagógico. In: BACKES, J. L.; OLIVEIRA, R.T.C.; PAVAN, R. (Orgs.). Políticas educacionais, currículo e diversidade cultural na Educação Básica. Campinas: Mercado das Letras, 2015, p.127-146.

FRANK, A. O diário de Anne Frank. Edição integral. Rio de Janeiro: Ed. Record, 2000.

FURNARI, Eva. Listas fabulosas. São Paulo: Moderna. 1.ed. 2013.

LARROSA, Jorge; RECHIA, Karen. $P$ de professor. São Carlos: Pedro \& João Editores, 2018.
MERLEAU-PONTY, Maurice. O olho e o espírito: seguido de $A$ linguagem indireta e as vozes do silêncio e A dúvida de Cézanne. Tradução de Paulo Neves e Maria Ermantina Galvão Gomes Pereira. São Paulo: Cosac \& Naify, 2004.

MORAIS, Artur Gomes de. Consciência fonológica na Educação Infantil e no Ciclo de Alfabetização. Belo Horizonte: Autêntica. 2019.

NARODOWSKI, Mariano. Onze teses urgentes para uma pedagogia do contra-isolamento. In: Pensar a Educação. Disponível em: https://pensaraeducacao.com.br/blogpensaraeducaca o/onze-teses-urgentes-para-uma-pedagogia-docontra-isolamento/ . Acesso em: 21 Maio. 2020.

NOLA, Lisa. Listografia: sua vida em listas. Tradução Rogério Durst. 1.ed. Rio de Janeiro: Intrínseca, 2014.

PERRENOUD, Philippe. Ensinar: agir na urgência, decidir na incerteza. Tradução de Claudia Schilling. Porto Alegre: Artmed Editora, 2001.

RECHIA, Karen Christiane; LARROSA, Jorge. Profissão ofício de professor. Sobre Tudo, 10, 23-46. 2019; Recuperado de: http://www.nexos.ufsc.br/index.php/sobretudo/article/v iewFile/3696/2767

NUNES, Marilia Forgearini; SPERRHAKE, Renata. Ensino Remoto e anos iniciais do ensino fundamental: reflexões em torno da docência e de algumas escolhas didáticopedagógicas para o ensino da leitura e da escrita. Signo, Santa Cruz do Sul, v. 46 , n. 85 , p. $26-34$, jan. 2021. ISSN $1982-2014$. Disponível em: $<$ https://online.unisc.br/seer/index.php/signo/article/view/157 10>. doi:https://doi.org/10.17058/signo.v46i85.15710. 